\title{
Induced deposition of bone-like hydroxyapatite on thermally oxidized titanium substrates using a spatial gap in a solution that mimics a body fluid
}

\author{
Atsushi SUGINO, ${ }^{\dagger}$ Kanji TSURU, ${ }^{*}$ Satoshi HAYAKAWA, ${ }^{* *}$ Koichi KIKUTA, ${ }^{* * *}$ Giichiro KAWACHI, ${ }^{* * *}$ \\ Akiyoshi OSAKA** and Chikara OHTSUKI*** \\ Nakashima Medical Co., Ltd., 688-1, Joto-Kitagata, Okayama-shi, Okayama 709-0625 \\ *Department of Biomaterials, Faculty of Dental Science, Kyushu University, \\ 3-1-1, Maidashi, Higashi-ku, Fukuoka-Shi, Fukuoka 812-8582 \\ ** Division of Chemical and Biological Chemistry, Graduate School of Natural Science and Technology, Okayama University, \\ 3-1-1, Tsushima-naka, Okayama-shi, Okayama 700-8630 \\ *** Department of Crystalline Materials Science, Graduate School of Engineering, Nagoya University, \\ Furo-cho, Chikusa-ku, Nagoya-shi, Aichi 464-8603
}

\begin{abstract}
We report on the effect of using a spatial gap on heterogeneous nucleation on the surface of thermally oxidized titanium substrates. Induction of heterogeneous nucleation of bone-like hydroxyapatite (BHAp) was evaluated in the spatial gaps between substrates that were thermally oxidized at temperatures of $100-800^{\circ} \mathrm{C}$ on exposure to a simulated body fluid (SBF). After soaking in a SBF for $7 \mathrm{~d}$, BHAp spontaneously deposited inside the gap on the surface of samples that were thermally oxidized at temperatures above $400^{\circ} \mathrm{C}$, but not on samples that were thermally oxidized at temperatures of $300^{\circ} \mathrm{C}$ or less. Among the substrates studied, BHAp particles were most readily deposited inside the gap on the surface of the samples that were thermally oxidized at $4^{\circ} 0^{\circ} \mathrm{C}$ after soaking in an SBF. A smaller gap led to a higher number of BHAp particles being deposited on the surface of the samples that were thermally oxidized at 400 or $500^{\circ} \mathrm{C}$. Our results suggest that the formation of BHAp in a SBF is dependent on the temperature during thermal oxidization, and also on the spatial gap between the samples. The ease of formation of BHAp on thermally oxidized titanium increases with increasing thickness of the rutile phase and the number of Ti-OH groups, which are produced during the thermal oxidization process. In addition to the surface structure of the substrates, the spatial gap is regarded as an important parameter for enhancing the deposition of BHAp. Since the formation of BHAp allows osteoconduction to occur after implantation in a bony defect, it is possible to design titanium-based implants with a high biological affinity to bone by processing using an appropriate spatial design of the substrate.
\end{abstract}

(02009 The Ceramic Society of Japan. All rights reserved.

Key-words : Titanium substrates, Bone-like hydroxyapatite, Spatial gap, Heterogeneous nucleation, Titanium oxide, Osteoconduction

[Received November 27, 2008; Accepted March 17, 2009]

\section{Introduction}

Titanium and its alloys are widely used in orthopedic and dental implants, such as artificial joints and artificial tooth roots, because they show a high biological affinity to bone tissue. The biological affinity of titanium-based implants is regarded as being a bioinert property of these materials. Hence, living bone appears to come close to the surface of these materials, but does not make a direct bond to implanted materials via a intervening layer that contains both proteoglycans and glucosaminoglycans. ${ }^{1)}$ Namely, titanium substrate and its alloys do not achieve "direct bonding" with bone. ${ }^{2)}$ Many researchers have reported that bioactive materials, such as hydroxyapatite ceramics $\left(\mathrm{Ca}_{10}\left(\mathrm{PO}_{4}\right)_{6}(\mathrm{OH})_{2}\right)$, Cerabone ${ }^{\circledR} \mathrm{A}-\mathrm{W}$, and Bioglass ${ }^{\circledR}$, can directly bond to living bone through a biologically active hydroxyapatite layer formed on a substrate after implantation in bony defects. ${ }^{3), 4)}$

Biologically active hydroxyapatite has similar characteristics to natural bone, and is abbreviated bone-like hydroxyapatite as

Corresponding author: A. Sugino; E-mail: a.sugino@ nakashima. co.jp
BHAp. The property where new bone is formed on the surface of a bioactive material is called osteoconduction. Osteoconduction of a bioactive material is caused by the formation of a BHAp layer in a bony defect after implantation, resulting in a direct bond to living bone. ${ }^{5), 6)}$ The potential for BHAp formation on a substrate in a bony defect is related to the osteoconductivity. The formation of BHAp on a substrate can be evaluated in vitro by exposing it to a simulated body fluid (SBF), as proposed by Kokubo and colleagues. ${ }^{7), 8)}$

A chemical treatment of titanium substrates has been used to enable the formation of BHAp, involving treating the titanium metal with an $\mathrm{NaOH}$ solution ${ }^{9), 10)}$ and an $\mathrm{H}_{2} \mathrm{O}_{2}$ solution, ${ }^{11), 12)}$ which is effective in inducing BHAp nucleation in a body environment. These treatments were developed based on the observation that $\mathrm{Ti}-\mathrm{OH}$ groups in titania hydrogels induce heterogeneous nucleation of BHAp in a SBF. ${ }^{13)}$ These chemically treated substrates are usually subjected to a heat-treatment to obtain a gradient structure of the osteoconductive surface that is suitable for a stable fixation between the substrate and the bone. Furthermore, Osaka and colleagues have found that deposition of hydroxyapatite in a SBF was improved after subsequent heat- 
treatments at approximately $400^{\circ} \mathrm{C}$, where the anatase phase was formed on a titanium substrate. ${ }^{14)}$ Osaka et al. also reported that BHAp was deposited on the surface of a normal oxidized substrate after a heat-treatment when the sample was soaked in a SBF using a special sample setup, where the substrate was placed on top of another sample, and the arrangement was bolstered with a piece of nylon wire. ${ }^{15-17)}$ In their experiment, BHAp was deposited on the internal surface of the oxidized substrates, between both samples. The area where the BHAp was deposited was influenced by the heat-treatment temperature. And the area covered with BHAp was the greatest on samples heated at $400^{\circ} \mathrm{C}$ for $1 \mathrm{~h}$.

Based on their findings, we hypothesized that a given type of oxidized titanium substrate may show a high potential for BHAp formation in a body environment when it was combined with a spatial design around the surface. This means that osteoconductive materials may be produced through a morphological design of the surface of a titanium substrate followed by a subsequent heat-treatment to an appropriate temperature, around $400^{\circ} \mathrm{C}$. However, the details on inducing BHAp deposition on a titanium substrate are not yet well understood. In this study, we focused on the effect of an initial deposition of BHAp in the spatial gap between oxidized titanium substrates at various temperatures. The number of BHAp particles deposited was estimated in terms of the spatial gap between the substrates.

\section{Experimental procedure}

Commercial pure titanium samples (Grade II in the Japanese Industrial Standard, JIS T7401-1) were purchased from Kobe Steel Ltd., Japan. The samples were in the form of plates with dimensions of $10 \times 20 \times 1 \mathrm{~mm}^{3}$ that were cut using an electrical discharge machine. These were washed for $2 \mathrm{~min}$ in an aqueous solution containing both $2.75 \mathrm{~mol} \cdot \mathrm{dm}^{-3}$ hydrofluoric acid and $3.94 \mathrm{~mol} \cdot \mathrm{dm}^{-3}$ nitric acid. The surface of the plates was polished with SiC paper up to \#2000 grade, followed by ultrasonic cleaning in ultrapure water and acetone for $30 \mathrm{~min}$. Thermal oxidization of the samples was performed for $1 \mathrm{~h}$ in air at various temperatures: $100,200,300,400,500$, and $800^{\circ} \mathrm{C}$. The samples oxidized at 600 and $700^{\circ} \mathrm{C}$ were not used in our investigations, as the surface of the oxidized substrates at these temperatures was nonuniform on visual observation.

The SBF was prepared following the method developed by Kokubo and colleagues. ${ }^{7), 8)}$ The SBF had an ion concentration of: $\mathrm{Na}^{+}=142.0, \mathrm{~K}^{+}=5.0, \mathrm{Mg}^{2+}=1.5, \mathrm{Ca}^{2+}=2.5, \mathrm{Cl}^{-}=147.8$, $\mathrm{HCO}_{3}{ }^{-}=4.2, \mathrm{HPO}_{4}{ }^{2-}=1.0$, and $\mathrm{SO}_{4}{ }^{2-}=0.5 \mathrm{~mol} \cdot \mathrm{m}^{-3}$, and $\mathrm{pH}=$ 7.40 at $36.5^{\circ} \mathrm{C}$. A specific spatial gap was established as shown in Fig. 1. To establish the internal gap between the substrates, the oxidized titanium samples were placed on the surface of a commercially available polytetrafluoroethylene (PTFE) plate, bolstered by two pieces of $1 \times 1 \times 1 \mathrm{~mm}^{3}$ acrylic cubes at one of the edges. After soaking in $30 \mathrm{~cm}^{3}$ of the SBF for 1,3 , and $7 \mathrm{~d}$, the titanium substrates were removed, washed gently in ultrapure water, and dried in air at room temperature.

The surface of the samples thermally oxidized at various temperatures before and after soaking in the SBF was characterized using a scanning electron microscope (SEM; JSM-5600, Jeol Ltd, Tokyo, Japan), X-ray diffraction (XRD, RINT2000, Rigaku Corp., Tokyo, Japan), laser Raman spectroscopy (NRS-1000, JASCO Corp., Tokyo, Japan), and X-ray photo spectroscopy (XPS, JPS-9000MC, Jeol Ltd., Tokyo, Japan). The XRD measurements were performed using a fixed time scanning mode with a step $=0.02^{\circ}$ and $t=2.0 \mathrm{~s}$ for each step, employing a $\mathrm{Cu} \mathrm{K} \alpha \mathrm{X}$-ray source. In the Raman spectroscopic measurements, a)

c)

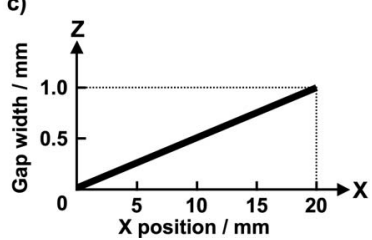

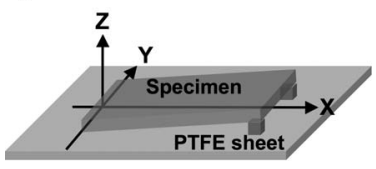

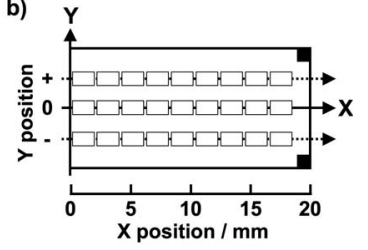

b)
Fig. 1. Scheme showing the sample setting for the designed spatial gap between the titanium substrate and a PTFE sheet. (a) Axis coordination for the observation of bone-like hydroxyapatite (BHAp) deposition. (b) Drawings from the $z$-axis perspective (the open squares denote the indicative areas under SEM observation). (c) Drawings from the $y$-axis perspective.

a single monochromator was used to obtain the Raman spectra that were excited using a laser operating in the green visible wavelength of $\lambda=532 \mathrm{~nm}$. The XPS measurements were performed using a take-off angle of $10^{\circ}$ employing an $\mathrm{Al} \mathrm{K} \alpha \mathrm{X}$-ray source. The $\mathrm{O} 1 \mathrm{~s}$ and $\mathrm{C} 1 \mathrm{~s}$ spectra were obtained and referenced by setting the hydrocarbon $\mathrm{C} 1 \mathrm{~s}$ peak to a value of $285.0 \mathrm{eV}$. The line shape of the O1s peak was fitted to a Gaussian model, and the background was assumed to be linear. In the SEM observations, several areas were observed on a single sample, as shown schematically in Fig. 1. Photographs of the area were taken for each $1 \mathrm{~mm}$ step along the $x$-axis from the lower end of the sample width until no deposition was observed, while three different areas along the $y$-axis were observed for a single sample: one in the center of the sample and the others at a distance of $\pm 2.5 \mathrm{~mm}$ from the center along the $y$-axis of the samples. The width of the internal gap between the titanium substrates and bottom PTFE plate was estimated from the distance from one of the edges of the sample. The number and size of deposited particles were evaluated from each SEM photograph using an image analysis software package (ImageJ, National Institutes of Health, MD, USA). The number of deposited particles was counted from each SEM image. The area of the deposited particles was measured by using the binary images converted from each SEM image. And then, the average size of the deposited particles was determined from the area of all the deposits divided by the number from each SEM image.

\section{Results}

Figure 2 shows the XRD patterns of titanium substrates thermally oxidized at various temperatures, as well as a non-treated sample, before soaking in a SBF. The peak occurring at $2 \theta=27^{\circ}$ was assigned to the (110) plane of titanium dioxide having the rutile structure, and was detected in samples that were thermally oxidized at temperatures above $400^{\circ} \mathrm{C}$. This peak was not detected in samples that were thermally oxidized at temperatures of $300^{\circ} \mathrm{C}$ and less. The peak occurring at $2 \theta=36^{\circ}$ was assigned to the (101) plane of rutile, and this was detected in the samples oxidized at $800^{\circ} \mathrm{C}$.

Figure 3 shows the Raman spectra of the surface of titanium substrates thermally oxidized at various temperatures. The Raman spectra of the surface of the samples thermally oxidized at temperatures above $200^{\circ} \mathrm{C}$ showed peaks occurring at 612 and 


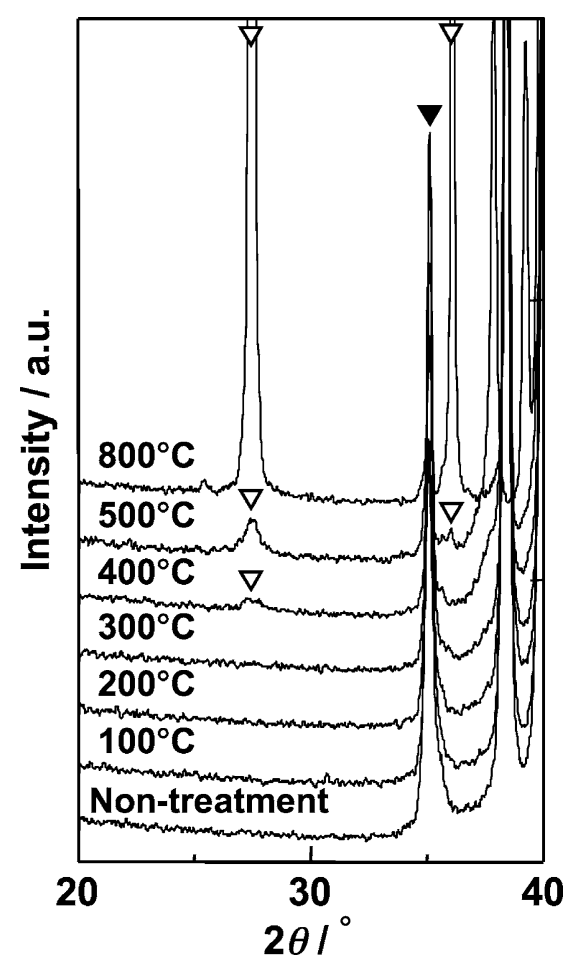

Fig. 2. XRD patterns of the titanium substrates thermally oxidized at various temperatures before soaking in a SBF. Open triangles were assigned to rutile (JCPDS card 21-1276). Closed triangles were assigned to $\alpha$-Ti (JCPDS card 44-1294).

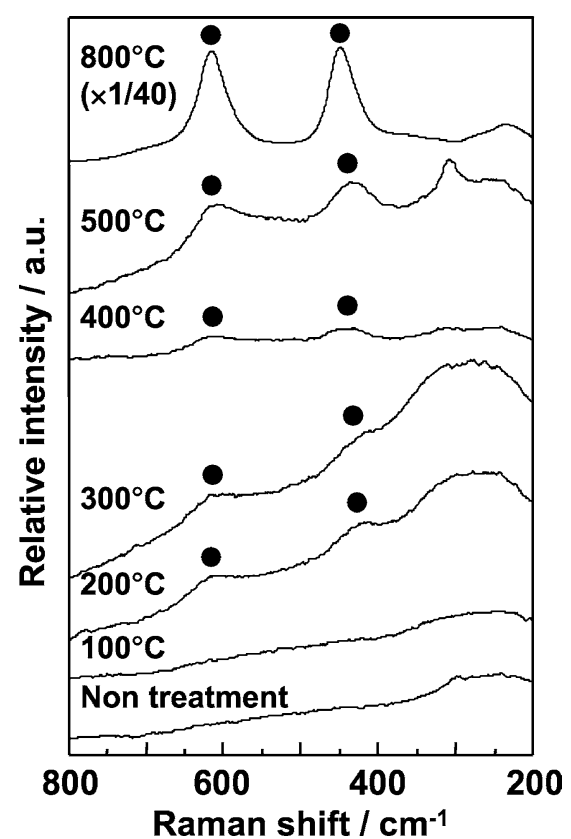

Fig. 3. Raman spectra of the titanium substrates thermally oxidized at various temperatures before soaking in a SBF. Closed circles were assigned to rutile.

$447 \mathrm{~cm}^{-1}$, which were assigned to the rutile phase of titanium dioxide. ${ }^{18), 19)}$ Samples that had not been heat treated (nontreatment) and samples that had been thermally oxidized at $100^{\circ} \mathrm{C}$ did not show any Raman peaks indicative of titanium oxide. The presence of rutile was confirmed on the substrates

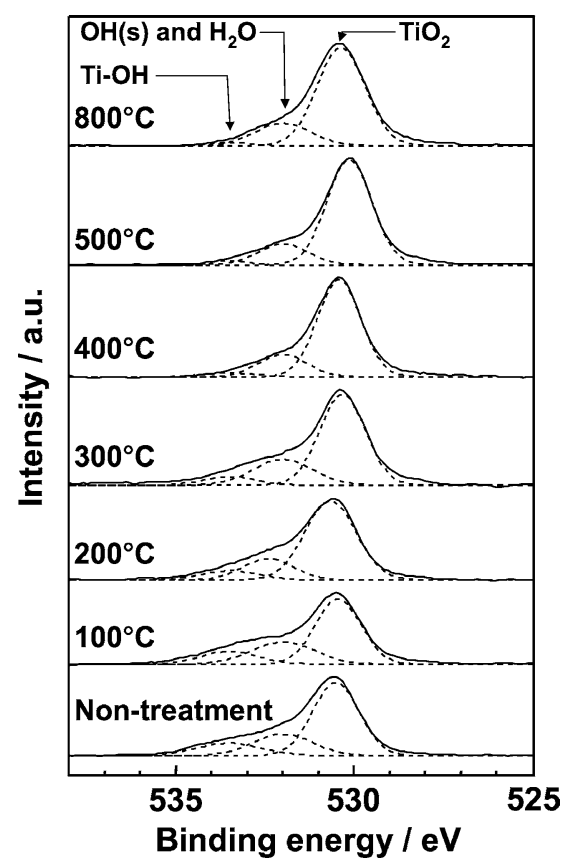

Fig. 4. XPS O1s spectra of the titanium substrates thermally oxidized at various temperatures before soaking in a SBF.

heated at temperatures of $200^{\circ} \mathrm{C}$ and above from the appearance of weak peaks at 611 and $447 \mathrm{~cm}^{-1}$. Peaks that were typically of rutile were detected in the Raman spectrum of the substrate heated at $800^{\circ} \mathrm{C}$. These results indicate that titanium dioxide was able to form on the substrates after they had been heat-treated at temperatures above $200^{\circ} \mathrm{C}$, and that the thickness of the oxide layer increased with increasing heat-treatment temperature, finally forming the rutile phase at a temperature of $800^{\circ} \mathrm{C}$.

Figure 4 shows the XPS O1s spectra of titanium substrates thermally oxidized at various temperatures before soaking in a SBF. The molecular species present in these spectra were assigned according to the literature report of Healy and colleagues. ${ }^{20), 21)}$ The major peak at $530.1 \mathrm{eV}$ was assigned to the bulk oxygen atoms of titanium dioxide. The decomposed peak at $531.6 \mathrm{eV}$ was attributed to physisorption of $\mathrm{H}_{2} \mathrm{O}$ and oxygen atoms that were doubly coordinated to titanium $(\mathrm{OH}(\mathrm{s}))$, while the peak at $533.3 \mathrm{eV}$ was ascribed to the chemisorption of $\mathrm{H}_{2} \mathrm{O}$, i.e., Ti-OH. The presence of $\mathrm{Ti}-\mathrm{OH}$ indicates that the oxygen atoms were singly coordinated. The intensity of the shoulder peaks including those at 531.6 and $533.3 \mathrm{eV}$ in the spectra decreased with increasing thermal oxidation temperature. This decrease is caused by dehydration and/or polycondensation and results in the formation of titanium dioxide. There remained a weak intensity from the peaks assigned to the Ti-OH groups after the heat treatment at temperatures of $400^{\circ} \mathrm{C}$ and above. The surface of the titanium substrate formed the rutile structure with less $\mathrm{Ti}-\mathrm{OH}$ groups after being thermally oxidized at temperatures above $400^{\circ} \mathrm{C}$.

Figure 5 shows that XRD patterns of titanium substrates thermally oxidized at various temperatures after soaking in a SBF for a period of $7 \mathrm{~d}$. Broad peaks occurring at $2 \theta=26^{\circ}$ and $32^{\circ}$ were detected in the diffraction patterns of the substrates thermally oxidized at 400 and $500^{\circ} \mathrm{C}$, followed by soaking in a SBF for a period of $7 \mathrm{~d}$. The broad peaks occurring at $2 \theta=26^{\circ}$ and $32^{\circ}$ were assigned to the (002) plane and to the envelope of the (211), (112), and (300) planes of low-crystalline hydroxyapatite, 


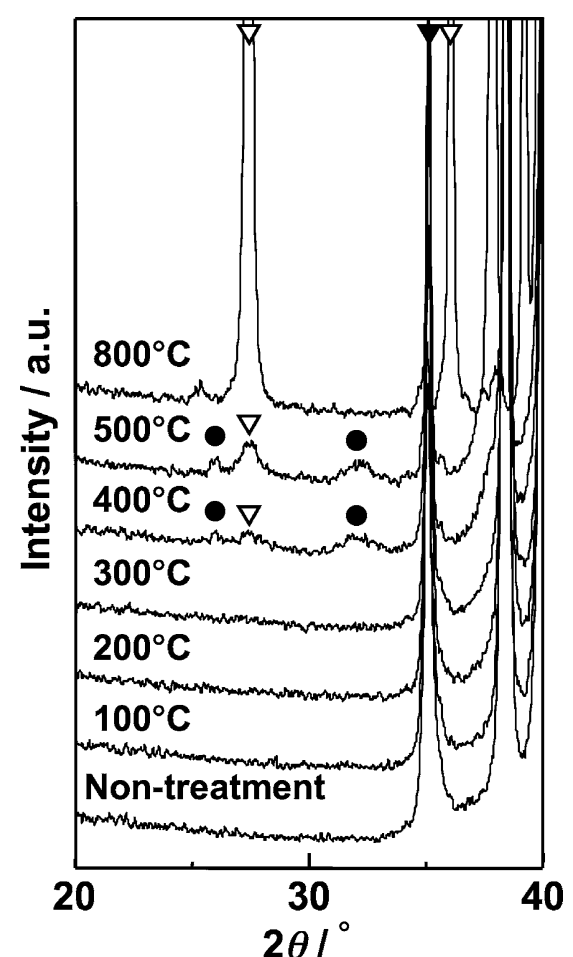

Fig. 5. XRD patterns of the titanium substrates thermally oxidized at various temperatures after soaking in a SBF for $7 \mathrm{~d}$. Closed circles were assigned to hydroxyapatite (JCPDS card 09-0432), open triangles were assigned to rutile (JCPDS card 21-1276), closed triangles were assigned to $\alpha$-Ti (JCPDS card 44-1294). respectively. In contrast, no peak assignable to hydroxyapatite was detected in the other samples after soaking in a SBF.

Figure 6 shows SEM photographs of the surface of the substrates established the specific gap before, and after, soaking in a SBF for a period of $7 \mathrm{~d}$. Spherical particles were observed on the surface of the substrates that were thermally oxidized at temperatures above $400^{\circ} \mathrm{C}$, followed by soaking in a $\mathrm{SBF}$ for a period of $7 \mathrm{~d}$. On the other hand, the morphology of the surface of the titanium substrates showed no change for the titanium substrates thermally oxidized at temperatures of $300^{\circ} \mathrm{C}$ and below. The deposited particles were attributed to the formation of BHAp, which did not form on the surface of titanium that was heat-treated at temperatures below $300^{\circ} \mathrm{C}$.

Figure 7 shows the number of deposited particles observed on the surface of titanium substrates thermally oxidized at 400, 500, and $800^{\circ} \mathrm{C}$ after soaking in a SBF for $7 \mathrm{~d}$. We note that the number of particles observed on the titanium substrates soaked in a SBF is related to the number of BHAp nuclei. Therefore, by carrying out a comparison at a given width of the gap, the number of BHAp nuclei increased with increasing heat-treatment temperature in the order: $800^{\circ} \mathrm{C}<500^{\circ} \mathrm{C}<400^{\circ} \mathrm{C}$. Among the substrates tested, the titanium substrates oxidized at $400^{\circ} \mathrm{C}$ showed the highest potential for inducing nucleation of BHAp. The number of BHAp nuclei on each substrate increased with decreasing gap width. Gap widths below $600 \mu \mathrm{m}$ induced nucleation of BHAp.

Figure 8 shows the number of BHAp particles observed on the surface of titanium substrates thermally oxidized at $400^{\circ} \mathrm{C}$ after soaking in a SBF for various periods. The examined gap widths of 150 and $400 \mu \mathrm{m}$ correspond to distances of 3 and $8 \mathrm{~mm}$ along
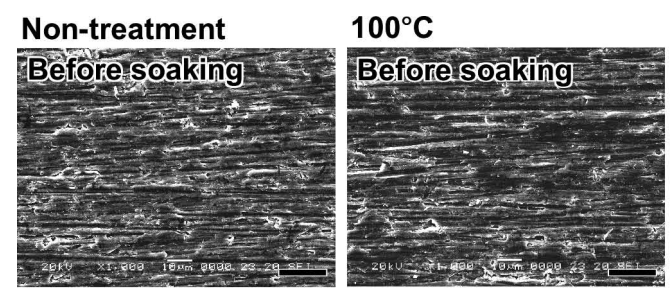

$200^{\circ} \mathrm{C}$

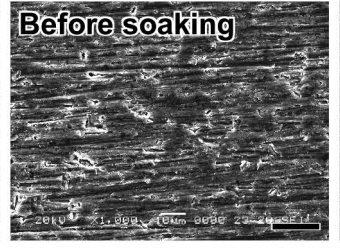

$300^{\circ} \mathrm{C}$
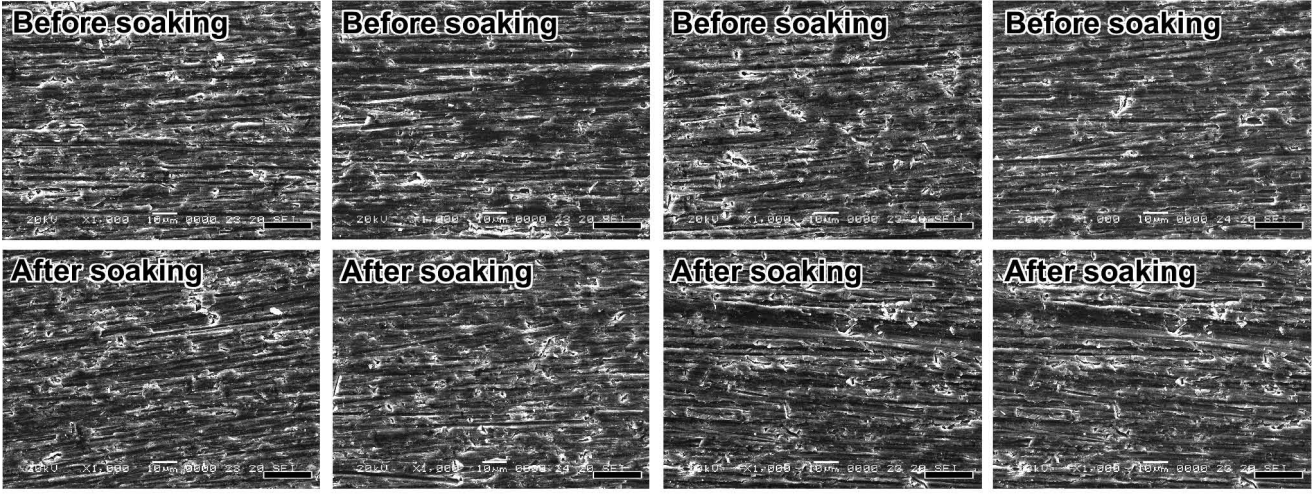

$400^{\circ} \mathrm{C}$

$500^{\circ} \mathrm{C}$

$800^{\circ} \mathrm{C}$
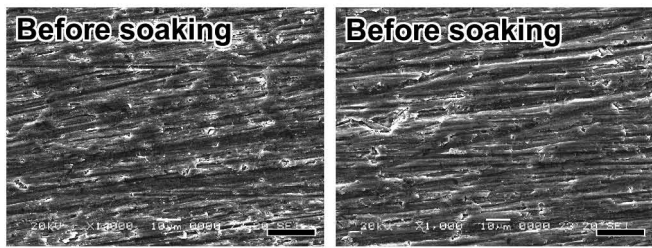

Before soaking
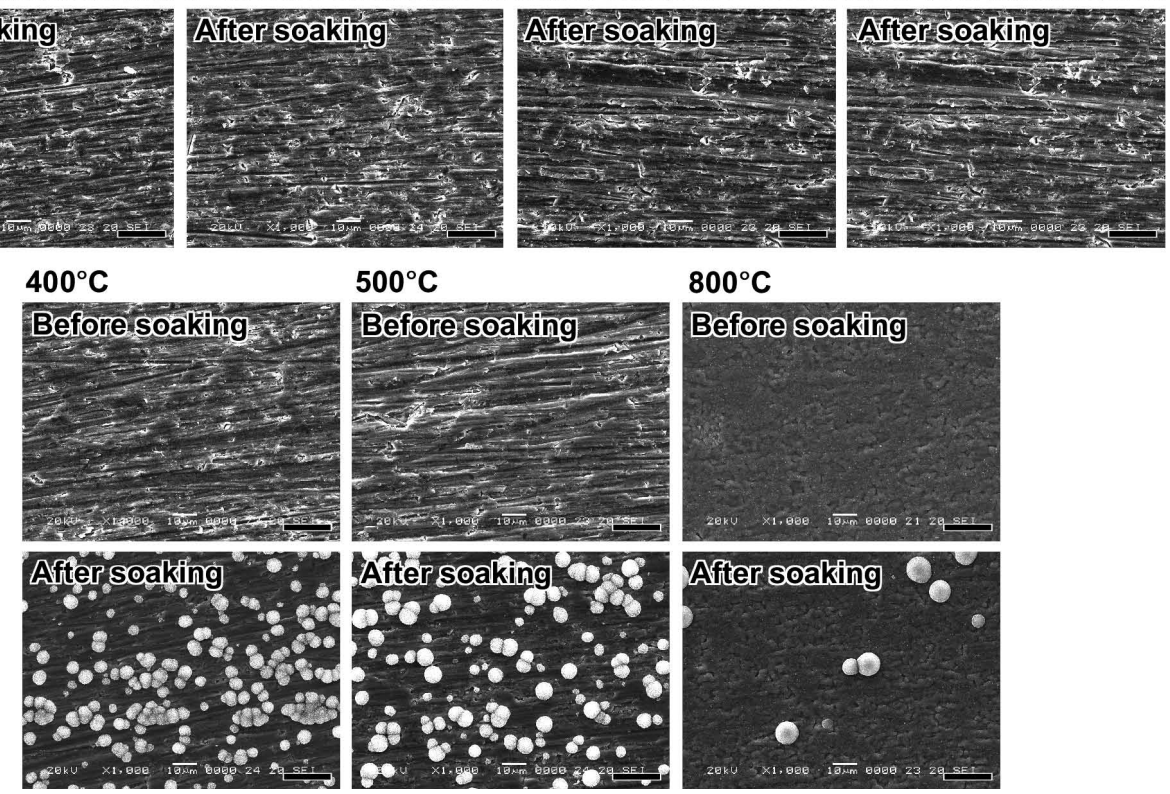

Fig. 6. SEM photographs of the surface of the titanium substrates thermally oxidized at various temperatures before and after soaking in a SBF for $7 \mathrm{~d}$ (scale bar $=20 \mu \mathrm{m}$ ). 


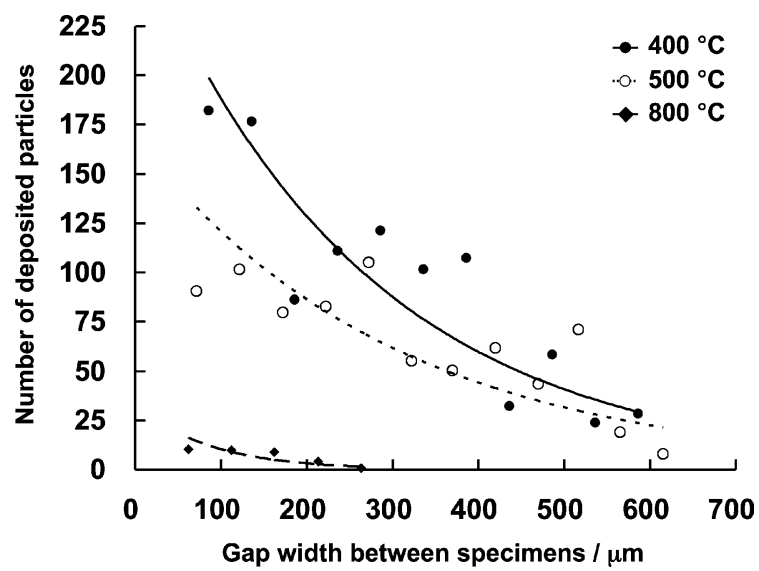

Fig. 7. Relationships between the gap width and the number of deposited particles on the surface of the titanium substrates thermally oxidized at 400,500 , or $800^{\circ} \mathrm{C}$ after soaking in a SBF for $7 \mathrm{~d}$. The closed circles, open circles, and closed rhombuses denote substrates oxidized at 400 , 500 , and $800^{\circ} \mathrm{C}$, respectively.

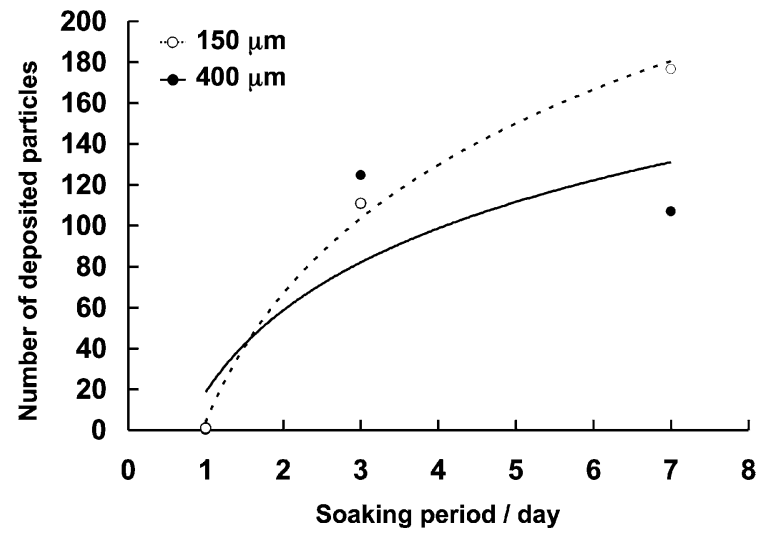

Fig. 8. Number of deposited particles on the surface of titanium substrates thermally oxidized at $400^{\circ} \mathrm{C}$ after soaking in a SBF for various periods. The examined gap widths of 150 and $400 \mu \mathrm{m}$ correspond to 3 and $8 \mathrm{~mm}$ at the $X$ position, respectively. The open circles with broken line and closed circles with full line denote the results at gap widths of 150 and $400 \mu \mathrm{m}$, respectively.

the $x$-direction, respectively. The number of the BHAp particles is regarded as an indicator of the frequency of nucleation on the surface of the substrates at each position. For either gap width, the number of BHAp particles showed a logarithmic increase with increasing soaking period. The degree of increase in the number of deposited BHAp particles with increasing soaking period for the gap with a width of $150 \mu \mathrm{m}$ was larger than for the gap with a width of $400 \mu \mathrm{m}$.

Figure 9 shows the size of the BHAp particles on the surface of titanium substrates thermally oxidized at $400^{\circ} \mathrm{C}$ after soaking in a SBF for various periods at the same examination position as indicated in Fig. 8. The increase in size of the particles corresponds to the growth of the BHAp crystals on the substrates. The rate of crystal growth for a gap width of $400 \mu \mathrm{m}$ was faster than the rate of crystal growth for a gap width of 150 $\mu \mathrm{m}$. This indicates that a higher rate of nucleation of BHAp was induced using a smaller gap width, but larger crystals were grown when using larger gap widths, i.e., for spatial gaps less than $600 \mu \mathrm{m}$.

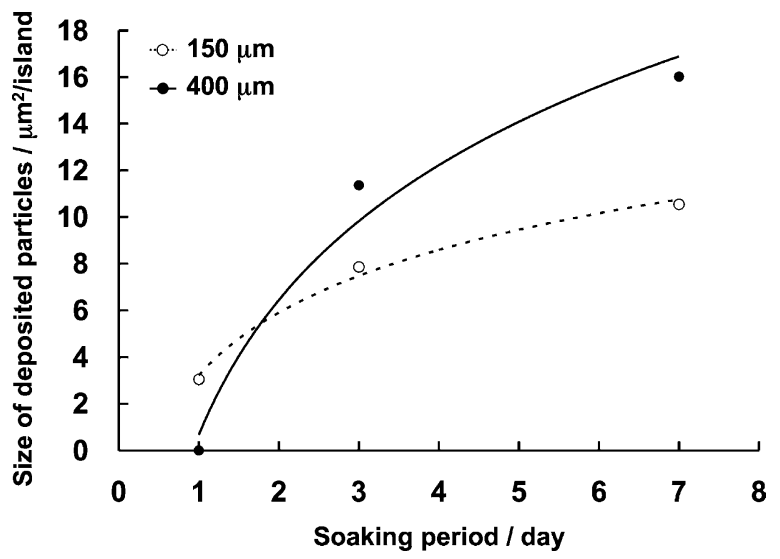

Fig. 9. Size of deposited particles on the surface of titanium substrates thermally oxidized at $400^{\circ} \mathrm{C}$ after soaking in a SBF for various periods. The examined gap widths of 150 and $400 \mu \mathrm{m}$ correspond to 3 and $8 \mathrm{~mm}$ at the $X$ position, respectively. The open circles with a broken line and closed circles with a full line denote the results at gap widths of 150 and $400 \mu \mathrm{m}$, respectively.

\section{Discussion}

The formation of BHAp in the substrate gap and the rate of nucleation of BHAp on the substrates were dependent on the heat-treatment conditions. The highest rate of formation of BHAp was observed on the surface of a titanium substrate treated at $400^{\circ} \mathrm{C}$. The SBF used was a metastable solution that was supersaturated with respect to hydroxyapatite. ${ }^{7,8)}$ In a previous study, the rate of heterogeneous nucleation of BHAp in a SBF was discussed in terms of the free energy for forming a critical-size cluster having the shape of a spherical cap, $\Delta \mathrm{Gs}^{*}$, as generally expressed by the following equation:

$$
\Delta G_{\mathrm{s}}^{*}=\Delta G^{*} f(\theta)
$$

where $\Delta G^{*}$ is the free energy of formation of an embryo of a critical size, and $f(\theta)$ is a function of the contact angle between the nucleus and the substrate. The term $f(\theta)$ relates to the surface characteristics of the surface of the titanium substrates used in this study. Hence, the surface on the titanium substrates after a heat treatment at $400^{\circ} \mathrm{C}$ provides the lowest value of $f(\theta)$ among the samples examined in this study. Although previous reports strongly suggest that the existence of $\mathrm{Ti}-\mathrm{OH}$ groups is important in the induction of BHAp nucleation in a $\mathrm{SBF},{ }^{13)}$ we did not observe the formation of BHAp on the substrates heat-treated at $300^{\circ} \mathrm{C}$ or below, although the XPS data showed that a large number of Ti-OH groups existed on samples heat-treated at lower temperatures (or even with no heat-treatment). These findings mean that the number of Ti-OH groups existing on the titanium substrate before exposure to a SBF may not determine the rate of nucleation of BHAp. A thick layer of titanium dioxide formed on the surface after the heat-treatment of the titanium substrates, while Ti-OH groups remained on their surface. This means that the nucleation of BHAp was induced under conditions where a given thickness of hydrated titanium dioxide layer was formed, even if Ti-OH groups existed on the substrate surface that could be identified using XPS characterization. Therefore, both a given thickness of titanium oxide, e.g., rutile, and the presence of $\mathrm{Ti}-\mathrm{OH}$ groups remaining on the substrate surface could cooperatively decrease the energy of the interface between the BHAp 
and the substrate, which would result in inducing BHAp nucleation.

The heterogeneous nucleation of BHAp on the surface of the titanium substrates in a SBF was influenced by the thermal oxidation temperature of the titanium samples and also by the width of the spatial gap. Previous studies have reported that titanium substrates thermally oxidized at $400^{\circ} \mathrm{C}$ do not deposit BHAp on their surface exposed to a SBF within a period of $7 \mathrm{~d}$ when they do not have a gap. ${ }^{14)}$ Therefore, both the spatial gap and the thermal oxidization stage of the titanium substrate cooperatively lead to the heterogeneous nucleation of BHAp on the titanium substrates in a body environment, such as in a SBF. The number of BHAp particles nucleated was directly influenced by the gap width between the substrates. Namely, narrower gap spaces showed higher rates of nucleation of BHAp on the substrate surface. We hypothesized that the nucleation of BHAp was influenced by a gap that would act in the role of capacitor, due to the surface charge on the titanium substrate. In this hypothesis, we qualitatively propose the relationship between the number of BHAp nuclei $\left(n_{\text {HAp }}\right)$ and the gap width $(\mathrm{h})$, as shown in the following equation:

$$
n_{\mathrm{HAp}}=f\left(n_{0}, \frac{1}{\varepsilon}, A, \frac{1}{h}\right)
$$

where $n_{0}$ is the rate of homogeneous nucleation of BHAp in a $\mathrm{SBF}$ at a certain degree of supersaturation of the solution with respect to hydroxyapatite, $\varepsilon$ is the dielectric constant of the SBF between the substrates, and $A$ is given by the electrical charge provided by the facing substrates in a SBF.

The effect of $A$ is determined by the combination of negative and/or positive charges on the sample in a SBF, as the electric field is dependent on the type of substrate. The samples in this study would provide an electrical repulsive force in a SBF against the PTFE plate, since the $\zeta$ potential of rutile and PTFE have been reported to be $-44.5 \mathrm{mV}$ at $\mathrm{pH}=7.3-7.5$ in a phosphate-buffered saline solution and $-55 \mathrm{mV}$ at $\mathrm{pH}=7.0$ in a $1 \mathrm{~mol} \cdot \mathrm{m}^{-3} \mathrm{KCl}$ solution, repectively. ${ }^{22), 23)}$ Narrower gap spaces invoke higher electrical repulsive forces, and these repulsive forces would be in order of the heat-treated substrates as: $400^{\circ} \mathrm{C}$ $>500^{\circ} \mathrm{C}>800^{\circ} \mathrm{C}$. This effect would result in the accumulation of cations, including the calcium ions, in the SBF on the Ti-OH groups of the oxide layer, and thereby, inducing heterogeneous nucleation of BHAp.

The crystal growth in a gap width of $400 \mu \mathrm{m}$ was larger than that in a gap width of $150 \mu \mathrm{m}$ in a SBF (see Fig. 9). This suggests that the diffusion of the ions in the gap may be a rate-determining process for BHAp growth in a SBF, because it is more difficult for the ions to diffuse in a narrower region after consumption of the calcium and phosphate ions to form BHAp.

\section{Conclusion}

Induction of BHAp was observed on the surface of titanium substrates with a specifically designed gap that were thermally oxidized at temperatures above $400^{\circ} \mathrm{C}$ after soaking in a SBF within a period of $7 \mathrm{~d}$. BHAp was not induced on titanium substrates heat-treated at temperatures of $300^{\circ} \mathrm{C}$ or less. Smaller gap widths enhanced the number of BHAp nucleation sites. The difference in the potential of the titanium substrates for nucleation of BHAp was attributed to the interfacial energy between the surface of the substrate and BHAp in the body environment. A lower interfacial energy was produced in the presence of $\mathrm{Ti}-\mathrm{OH}$ groups on the substrate, and for a thicker titanium dioxide layer. The effect of the gap on the heterogeneous nucleation of BHAp seems to be due to the electric field generated between the titanium substrate and the opposing PTFE plate. These findings reveal the importance of designing the surface morphology of titanium implants, followed by oxidization, to induce osteoconductivity, and the use of spatial design of the titanium implant.

\section{References}

1) T. Albrektsson, P.-I. Brånemark, H.-A. Hansson, B. Kasemo, K. Larsson, I. Lundström, D. H. McQueen and R. Skalak, Ann. Biomed. Eng., 11, 1-27 (1983).

2) T. Kokubo, H.-M. Kim, M. Kawashita and T. Nakamura, $J$. Mater. Sci. Mater. Med., 15, 99-107 (2004).

3) M. Neo, T. Nakamura, C. Ohtsuki, T. Kokubo and T. Yamamuro, J. Biomed. Mater. Res., 27, 999-1006 (1993).

4) L. L. Hench, J. Am. Ceram. Soc., 81, 1705-1728 (1998).

5) T. Kokubo, J. Ceram. Soc. Japan (Seramikkusu Ronbunshi), 99, 965-973 (1991).

6) H.-M. Kim, J. Ceram. Soc. Japan, 109, S49-S57 (2001).

7) T. Kokubo, H. Kushitani, S. Sakka, T. Kitsugi and T. Yamamuro, J. Biomed. Mater. Res., 24, 721-734 (1990).

8) T. Kokubo and H. Takadama, Biomaterials, 27, 2907-2915 (2006).

9) H.-M. Kim, F. Miyaji, T. Kokubo and T. Nakamura, $J$. Biomed. Mater. Res., 32, 409-417 (1996).

10) M. Uchida, H.-M. Kim, T. Kokubo, S. Fujibayashi and T. Nakamura, J. Biomed. Mater. Res. (Appl. Biomater.), 63, 522-530 (2002).

11) C. Ohtsuki, H. Iida, S. Hayakawa and A. Osaka, J. Biomed. Mater. Res., 35, 39-47 (1997).

12) X.-X. Wang, S. Hayakawa, K. Tsuru and A. Osaka, J. Biomed. Mater. Res., 54, 172-178 (2001).

13) P. Li, C. Ohtsuki, T. Kokubo, K. Nakanishi, N. Soga and K. de Groot, J. Biomed. Mater. Res., 28, 7-15 (1994).

14) X.-X. Wang, S. Hayakawa, K. Tsuru and A. Osaka, J. Biomed. Mater. Res., 52, 171-176 (2000).

15) X.-X. Wang, W. Yan, S. Hayakawa, K. Tsuru and A. Osaka, Biomaterials, 24, 4631-4637 (2003).

16) A. Sugino, K. Uetsuki, K. Tsuru, S. Hayakawa, C. Ohtsuki and A. Osaka, Key Eng. Mater., 361-363, 621-624 (2008).

17) A. Sugino, K. Uetsuki, K. Tsuru, S. Hayakawa, A. Osaka and C. Ohtsuki, Mater. Trans., 49, 428-434 (2008).

18) U. Balachandran and N. G. Eror, J. Solid State Chem., 42, 276-282 (1982).

19) J. C. Parker and R. W. Siegel, Appl. Phys. Lett., 27, 943-945 (1990).

20) K. E. Hearly and P. Ducheyne, J. Biomed. Mater. Res., 26, 319-338 (1992).

21) K. E. Healy and P. Ducheyne, Biomaterials, 13, 553-561 (1992).

22) W. Wu and G. H. Nancollas, J. Coll. Inter. Sci., 199, 206-211 (1998).

23) U. Meyer, S. Köstler, V. Ribitsch and W. Kern, Macromol. Chem. Phys., 206, 210-217 (2005). 